\title{
The effect of electromagnetic radiation emitted by display screens on cell oxygen metabolism - in vitro studies
}

\author{
Małgorzata Lewicka ${ }^{1}$, Gabriela A. Henrykowska ${ }^{1}$, Krzysztof Pacholski², Janusz Śmigielski ${ }^{3}$, \\ Maciej Rutkowski ${ }^{4}$, Maria Dziedziczak-Buczyńska ${ }^{1}$, Andrzej Buczyński ${ }^{1}$
}

\begin{abstract}
${ }^{1}$ Department of Epidemiology and Public Health, Medical University of Lodz, Lodz, Poland

${ }^{2}$ Institute of Electrical Engineering System, Technical University of Lodz, Lodz, Poland ${ }^{3}$ Department of Computer Science and Medical Statistics, Medical University of Lodz, Lodz, Poland

${ }^{4}$ Department of Military Toxicology and Radiological Protection, Medical University of Lodz, Lodz, Poland
\end{abstract}

Submitted: 26 July 2013

Accepted: 15 December 2013

Arch Med Sci 2015; 11, 6: 1330-1339

DOI: 10.5114 /aoms.2015.56362

Copyright $\odot 2015$ Termedia \& Banach

\section{Abstract}

Introduction: Research studies carried out for decades have not solved the problem of the effect of electromagnetic radiation of various frequency and strength on the human organism. Due to this fact, we decided to investigate the changes taking place in human blood platelets under the effect of electromagnetic radiation (EMR) emitted by LCD monitors.

Material and methods: The changes of selected parameters of oxygen metabolism were measured, i.e. reactive oxygen species concentration, enzymatic activity of antioxidant defence proteins - superoxide dismutase (SOD-1) and catalase (CAT) - and malondialdehyde concentration (MDA). A suspension of human blood platelets was exposed to electromagnetic radiation of $1 \mathrm{kHz}$ frequency and $150 \mathrm{~V} / \mathrm{m}$ and $220 \mathrm{~V} / \mathrm{m}$ intensity for 30 and $60 \mathrm{~min}$. The level of changes of the selected parameters of oxidative stress was determined after the exposure and compared to the control samples (not exposed).

Results: The measurements revealed an increase of the concentration of reactive oxygen species. The largest increase of ROS concentration vs. the control sample was observed after exposure to EMF of $220 \mathrm{~V} / \mathrm{m}$ intensity for $60 \min$ (from $x=54.64$ to $x=72.92$ ). The measurement of MDA concentration demonstrated a statistically significant increase after 30-min exposure to an $\mathrm{EMF}$ of $220 \mathrm{~V} / \mathrm{m}$ intensity in relation to the initial values (from $x=3.18$ to $x=4.41$ ). The enzymatic activity of SOD-1 decreased after exposure (the most prominent change was observed after $60-\mathrm{min}$ and $220 \mathrm{~V} / \mathrm{m}$ intensity from $x=3556.41$ to $x=1084.83$ ). The most significant change in activity of catalase was observed after $60 \mathrm{~min}$ and $220 \mathrm{v} / \mathrm{m}$ exposure (from $x=6.28$ to $x=4.15$ ).

Conclusions: The findings indicate that exposure to electromagnetic radiation of $1 \mathrm{kHz}$ frequency and $150 \mathrm{~V} / \mathrm{m}$ and $220 \mathrm{~V} / \mathrm{m}$ intensity may cause adverse effects within blood platelets' oxygen metabolism and thus may lead to physiological dysfunction of the organism.

Key words: LCD monitors, reactive oxygen species, malondialdehyde, superoxide dismutase, catalase.

\author{
Corresponding author: \\ Małgorzata Lewicka PhD \\ Department of Epidemiology \\ and Public Health \\ Medical University of Lodz \\ 7/9 Żeligowskiego St \\ 90-752 Lodz, Poland \\ Phone: +48 426393260 \\ Fax: +48 426393260 \\ E-mail: malgorzata.lewicka@ \\ umed.lodz.pl
}




\section{Introduction}

Studies on the effect of electromagnetic radiation (EMR) of different parameters on living organisms have been carried out for years. Already at the beginning of the 1960s, in the Soviet Union, Asanowi and Rakov determined the effect of this factor on the health of workers staying close to a power transmission line and exposed to an electric field of the intensity up to $26 \mathrm{kV} / \mathrm{m}$. The results of these studies demonstrated that this kind of exposure can cause functional disorders within the autonomic and central nervous system [1]. Other studies concerned the effect of EMR on different systems and organs and on their functions in living organisms as well as on subjective ailments, e.g. fatigue, headache, dizziness, nausea, sleep disorder, loss of appetite, and irritation. The results of some of these studies did not demonstrate a negative effect of EMR on human health and life [2-4].

Due to the fact that the results of scientific studies are ambiguous and that there are few studies carried out on human cells, especially regarding extremely low frequency (ELF) and electrical components of the field, the authors decided to investigate the effect of EMR emitted by LCD monitors on the parameters of oxidative stress in human blood platelets. Oxidative stress, defined as an imbalance of the pro-oxidant/antioxidant equilibrium, arises due to uncontrolled increase of reactive oxygen species (ROS) production and to the change of enzymatic activity of antioxidant defence proteins, e.g. superoxide dismutase and catalase.

The aim of the study was to determine changes taking place in blood platelets under the effect of electromagnetic radiation generated by common- ly used LCD monitors. This radiation is characterized by $1 \mathrm{kHz}$ frequency and $150 \mathrm{~V} / \mathrm{m}$ intensity at a distance of $30 \mathrm{~cm}$ from the monitor screen and $220 \mathrm{~V} / \mathrm{m}$ at $15 \mathrm{~cm}$. The tested sample was exposed to the electromagnetic field for 30 and $60 \mathrm{~min}$. The following parameters of blood platelet oxygen metabolism were investigated: ROS concentration, enzymatic activity of superoxide dismutase (SOD-1), enzymatic activity of catalase, and concentration of malondialdehyde (MDA) a marker of membrane lipid peroxidation.

\section{Material and methods}

\section{Sample preparation}

A suspension of human blood platelets at the concentration of $1 \times 10^{9} / \mathrm{cm}^{3}$, obtained by manual apheresis from whole blood, was the material for the study. The preparation was obtained from the Blood Donation Centre from voluntary blood donors who underwent medical examinations (those who had contraindications for blood drawing were excluded) and laboratory tests typical for blood donors were performed. Blood donors were healthy people, not taking any medication, staying on a mixed, average-calorie diet aged 25-45. The blood was transported to the laboratory in a box shielding against any radiation material.

\section{Exposure condition setting and instruments}

In a laboratory stand designed for reconstruction of the parameters of electromagnetic radiation generated by display screens $(1 \mathrm{kHz}, 150 \mathrm{~V} / \mathrm{m}$, $220 \mathrm{~V} / \mathrm{m}$ ), a flat capacitor was the source of the electromagnetic field (Figure 1). Requirements of

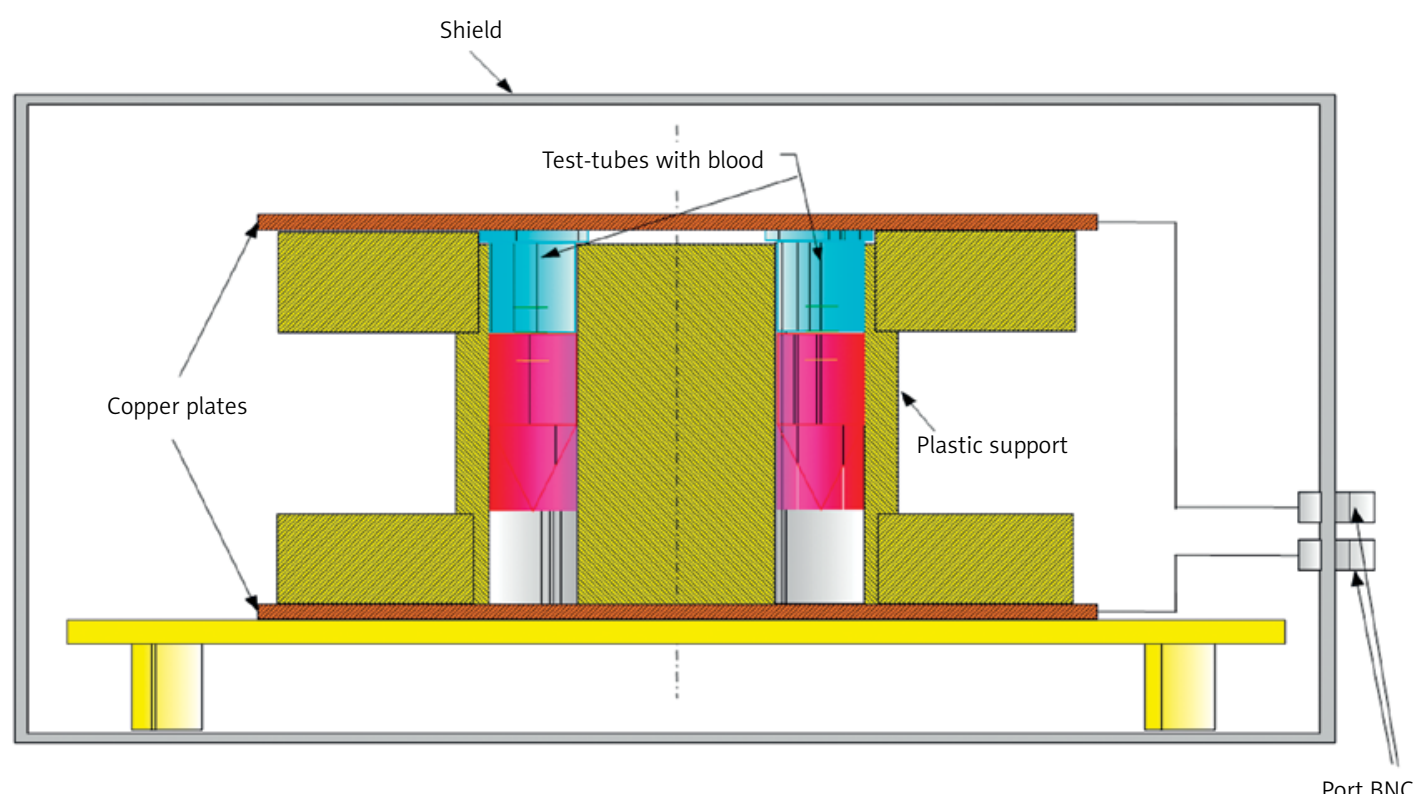

Figure 1. Laboratory stand designed for reconstruction of the parameters of electromagnetic radiation generated by display screens 
the TCO (the Swedish Confederation of Professional Employees) and MPR (the National Board for Measurement and Testing) specify strict conditions for the measurement of exposure. The authors measured the field by the measurement procedure at the location of points placed in front of the monitor.

When electromagnetic radiation of low frequency is tested, the electric and magnetic components should be investigated independently. Monitors with liquid crystal screens produce non-sinusoidal electromagnetic fields, with the dominant electric component, due to control of power semiconductor chips. Significant fields as regards their effect on the human body are fields with frequency of lower power consumption and voltage switching power supply, with superimposed oscillation dampened RLC circuits, which act as voltage ripple smoothing filters. The source of the signal simulating shape of the field generated by the LCD was the programmable generator Hameg 8010 , which is amplified by the measuring amplifier W-320, and the source of the electric field was a flat capacitor arrangement. The capacitor was formed by two circular copper plates positioned over and under a plastic support in which 8 polyethylene tubes containing the tested preparation were inserted into holes made symmetrically on the circumference of the circle, the diameter of which was smaller than that of the capacitor plates so that the electrical component of the field acting on the tubes was homogeneous in nature. The tested preparation was placed in polyethylene tubes, each containing $3 \mathrm{ml}$ of the preparation. The temperature in the laboratory stand was at the same level all the time, i.e. $+24 /+25^{\circ} \mathrm{C}$. Preserving constant conditions of the environment, the preparation was exposed to the activity of the electromagnetic field of $1 \mathrm{kHz}$ frequency and $150 \mathrm{~V} / \mathrm{m}$ intensity (corresponding to a distance of $30 \mathrm{~cm}$ from the monitor) and $220 \mathrm{~V} / \mathrm{m}$ intensity (corresponding to a distance of $15 \mathrm{~cm}$ from the monitor) for 30 and $60 \mathrm{~min}$. The exposure of the platelets to the radiation was done on the day they were collected from the Blood Donation Centre.

\section{Measurement of reactive oxygen species and antioxidant activity of superoxide dismutase, catalase and malondialdehyde concentration}

The selected parameters of oxidative stress were measured before and immediately after the exposure. The level of ROS generation, enzymatic activity of antioxidant defence proteins (superoxide dismutase and catalase) and the concentration of malondialdehyde (MDA) as a marker of lipid peroxidation were determined. Chemiluminescence (emission of light as the result of chemical reaction) was used to determine ROS concen- tration. After stimulation of platelet-activating factor there occurs simultaneous increase of cell metabolism associated with an elevated demand for oxygen. It results in oxidative burst generating reactive oxygen species which initiate a cascade of reactions leading to formation of different compounds which in turn lose their energy in the form of light radiation. This emission of light (chemiluminescence) accompanying oxidative burst was measured using a Lumicom luminometer (HAMILTON) connected to an IBM PC. Simultaneously sequential measurement was performed for 6 samples for $30 \mathrm{~min}$. The tested samples consisted of $200 \mu$ lof blood platelet suspension of the concentration $1 \times 10^{9} / \mathrm{cm}^{3}, 20 \mu \mathrm{l}$ of luminol, and $780 \mu \mathrm{l}$ of phosphate-buffered saline (PBS) (a buffer solution of salt to $\mathrm{pH} 7.2$ ). The obtained results were compared with the control sample of $200 \mu \mathrm{l}$ of platelet suspension not exposed to an electromagnetic field (EMF), $20 \mu$ l of luminol, and $780 \mu$ l of PBS. We used 36 control samples and 36 exposed samples.

A CARY 100 BIO spectrophotometer (VARIAN) was used for the measurement of superoxide dismutase activity at $480 \mathrm{~nm}$ wavelength. Absorbance in the control and study samples was measured every minute at $+25^{\circ} \mathrm{C}$ for $5 \mathrm{~min}$. The study samples were obtained by adding $0.2 \mathrm{~cm}^{3}$ of platelet suspension at the concentration of $1 \times 10^{9} / \mathrm{cm}^{3}$, $0.8 \mathrm{~cm}^{3}$ of redistilled water cooled to $+4^{\circ} \mathrm{C}$ and $0.5 \mathrm{~cm}^{3}$ of $96 \% \mathrm{C}_{2} \mathrm{H}_{5} \mathrm{OH}$ and $0.25 \mathrm{~cm}^{3}$ chloroform. The obtained mixture was shaken for $2 \mathrm{~min}$ and then centrifuged at $4200 \times \mathrm{g}$ at $+4^{\circ} \mathrm{C}$ for $10 \mathrm{~min}$. After centrifugation, the enzyme remained in the upper layer of the suspension. Then $0.2 \mathrm{~cm}^{3}$ of supernatant was transferred into glass tubes together with $2.6 \mathrm{~cm}^{3}$ of $0.05 \mathrm{M}$ carbonate buffer of $\mathrm{pH}$ 10.2 and $0.2 \mathrm{~cm}^{3}$ of adrenaline. The blind test did not contain supernatant; the carbonate buffer was used instead. The values were presented in $\mathrm{U} / \mathrm{g}$ of platelet protein. The amount of enzyme which causes $50 \%$ inhibition at the maximal increase of absorbance by 0.025 of unit/min on a rectilinear segment of adrenochrome formation at $+25^{\circ} \mathrm{C}$ at $480 \mathrm{~nm}$ is defined as a unit of SOD activity [5]. We used 37 control and exposed samples.

To determine the catalase enzymatic activity, the suspension of blood platelets was frozen and thawed several times before the cell disintegration occurred. After centrifugation of the whole system at $4200 \times \mathrm{g}$ at $+4^{\circ} \mathrm{C}$ for $10 \mathrm{~min}$, a clear supernatant was obtained.

The measurement was performed using a CARY 100 BIO (VARIAN) spectrophotometer at $240 \mathrm{~nm}$ wavelength at $+25^{\circ} \mathrm{C}$ and absorbance was measured every minute for $5 \mathrm{~min}$. The control sample contained $3 \mathrm{~cm}^{3}$ of $0.05 \mathrm{M}$ phosphate buffer, whereas the study sample contained $2 \mathrm{~cm}^{3}$ of $0.05 \mathrm{M}$ phosphate buffer, $50 \mu \mathrm{l}$ of supernatant 
and $1 \mathrm{~cm}^{3}$ of $0.1 \% \mathrm{H}_{2} \mathrm{O}_{2}$. The obtained values were presented in Bergmeyer units per gram of platelet protein. One Bergmeyer unit $(U)$ determines the amount of catalase which decomposes $1 \mathrm{~g}$ of $\mathrm{H}_{2} \mathrm{O}_{2}$ per min at $+25^{\circ} \mathrm{C}$ at pH 7.0 [6]. We used 37 control and exposed samples.

The concentration of malondialdehyde was determined by measuring the absorbance on the CARY $100 \mathrm{BIO}$ spectrophotometer (VARIAN) at $532 \mathrm{~nm}$ wavelength vs. the control sample $\left(1.8 \mathrm{~cm}^{3}\right.$ PBS $+0.4 \mathrm{~cm}^{3}$ thiobarbituric acid). The study sample was prepared by adding $1 \mathrm{~cm}^{3}$ of $20 \%$ trichloroacetic acid (TCA) to $1 \mathrm{~cm}^{3}$ of blood platelet suspension at the concentration of $1 \times 10^{9} / \mathrm{cm}^{3}$; then the mixture was shaken for $1 \mathrm{~h}$ at $+4^{\circ} \mathrm{C}$ and centrifuged at $4200 \times \mathrm{g}$ at $+4^{\circ} \mathrm{C}$ for $15 \mathrm{~min}$. To $1.8 \mathrm{~cm}^{3}$ of the obtained supernatant $0.4 \mathrm{~cm}^{3}$ of $0.12 \mathrm{M}$ thiobarbituric acid was added. The mixture was placed in a boiling water bath for 15 min. After cooling, the obtained solution was centrifuged at $3000 \times \mathrm{g}$ for $10 \mathrm{~min}$ at room temperature. The obtained results were expressed in $\mathrm{nmol} / 10^{9}$ of platelets [7]. We used 36 control and exposed samples.

\section{Statistical analysis}

The following statistical parameters were determined for each of the characteristics in the study groups: arithmetic mean, standard deviation, median modal, and skewness coefficient. The obtained results were analysed using a nonparametric Kruskal-Wallis ANOVA rank test equivalent to analysis of variance and Mann-Whitney $U$ test to compare the variables between the groups. The analysis of empirical distributions of the tested parameters was performed with Shapiro-Wilk $W$ test. The value of $p<0.05$ was considered the level of significance.

\section{Results}

In the in vitro study, oxygen activity in blood platelets, expressed by the concentration of reactive oxygen species, stimulated by the electromagnetic field generated by monitor screens, increased significantly compared to the control values (Figure 2). The largest increase of ROS concentration vs. the control sample was observed after exposure to EMF of $220 \mathrm{~V} / \mathrm{m}$ intensity for $60 \mathrm{~min}$ (from $x=54.64$ to $x=72.92$ ). After exposure to EMF of

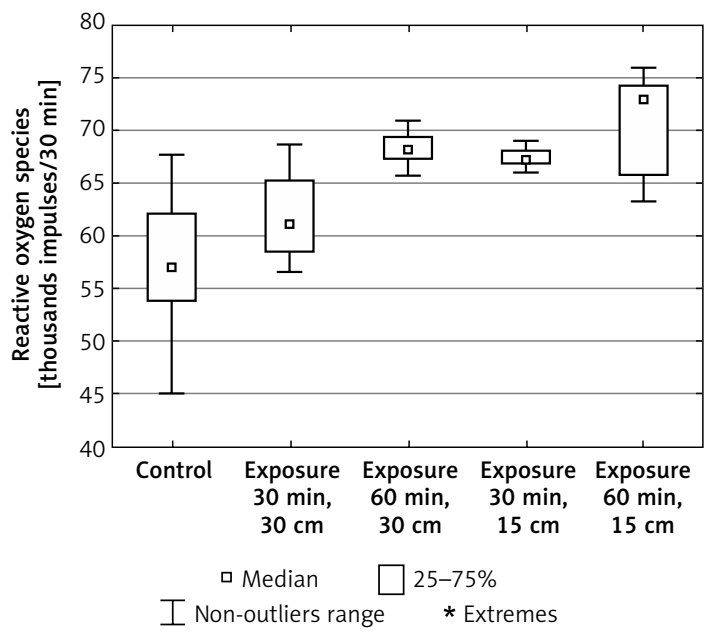

Figure 2. Concentration of reactive oxygen species in blood platelets exposed to electromagnetic radiation dependent on the intensity and exposure time $(n=36)$

Table I. Statistical analysis of changes in levels of reactive oxygen species in blood platelets exposed to electromagnetic radiation of defined parameters and exposure time

\begin{tabular}{|c|c|c|c|c|c|}
\hline \multirow{2}{*}{$\begin{array}{l}\text { Name of the } \\
\text { characteristic }\end{array}$} & \multirow{2}{*}{$\begin{array}{l}\text { Control } \\
\text { group }\end{array}$} & \multicolumn{4}{|c|}{ Exposure to electromagnetic radiation of the parameters and time } \\
\hline & & $\begin{array}{l}\text { Intensity: } \\
150 \mathrm{~V} / \mathrm{m}(30 \mathrm{~cm}) \\
30 \mathrm{~min} \\
\text { Group I }\end{array}$ & $\begin{array}{l}\text { Intensity: } \\
150 \mathrm{~V} / \mathrm{m}(30 \mathrm{~cm}) \\
60 \mathrm{~min} \\
\text { Group II }\end{array}$ & $\begin{array}{l}\text { Intensity: } \\
220 \mathrm{~V} / \mathrm{m}(15 \mathrm{~cm}) \\
30 \mathrm{~min} \\
\text { Group III }\end{array}$ & $\begin{array}{l}\text { Intensity: } \\
220 \mathrm{~V} / \mathrm{m}(15 \mathrm{~cm}) \\
60 \mathrm{~min} \\
\text { Group IV }\end{array}$ \\
\hline $\begin{array}{l}\text { Number of } \\
\text { individuals }\end{array}$ & 36 & 36 & 36 & 36 & 36 \\
\hline Minimum & 45.45 & 56.63 & 65.73 & 66.01 & 63.21 \\
\hline Maximum & 65.95 & 68.72 & 70.87 & 68.96 & 75.94 \\
\hline Median & 54.64 & 61.06 & 68.10 & 67.36 & 72.92 \\
\hline Arithmetic mean & 54.87 & 61.76 & 68.30 & 67.43 & 70.83 \\
\hline SD & 6.16 & 3.98 & 1.39 & 0.82 & 4.34 \\
\hline Skewness & -0.04 & 0.46 & 0.29 & 0.34 & -0.62 \\
\hline Statistical analysis & \multicolumn{5}{|c|}{$\begin{array}{l}\text { Test Anova rang Kruskala_Wallisa } H=145.42, p<0.001 \\
\text { Test } Z^{\mathrm{k}, \mathrm{I}}{ }_{\text {Manna-Whitneya }}=-4,56, p<0.001 \\
\text { Test } Z^{\mathrm{k}, \mathrm{II}}{ }_{\text {Manna-Whitneya }}=-7.29, p<0.001 \\
\text { Test } Z^{\mathrm{k}, \mathrm{III}} \text { Manna-Whitneya }=-7.30, p<0.001 \\
\text { Test } Z^{\mathrm{k}, \mathrm{IV}}{ }_{\text {Manna-Whitneya }}=-7,11, p<0.001\end{array}$} \\
\hline
\end{tabular}




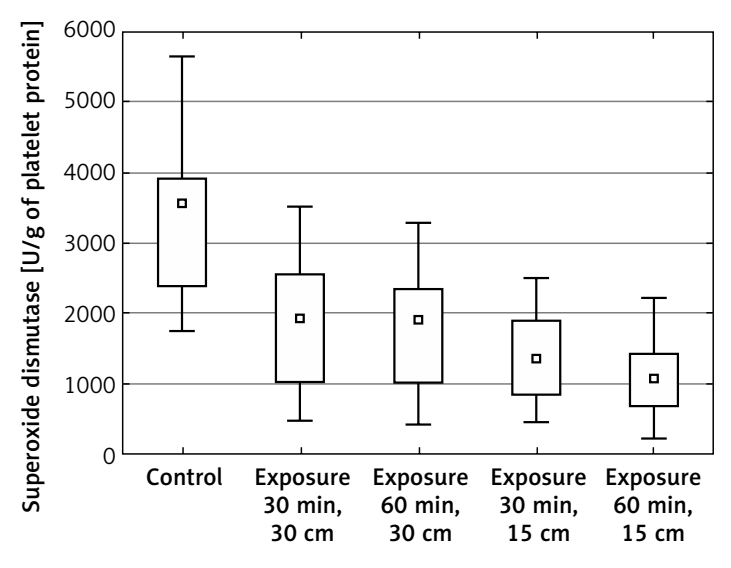

- Median $\square 25-75 \% \quad$ I Non-outliers range

Figure 3. Enzymatic activity of superoxide dismutase (SOD-1) in blood platelets exposed to electromagnetic field dependent on the intensity and exposure time $(n=37)$

$150 \mathrm{~V} / \mathrm{m}$ intensity the concentration of ROS increased in relation to the initial values from $x=$ 54.64 to $x=61.06$ (30-min exposure) and to $x=$ 68.10 (60-min exposure). After 30-min exposure to the field of $220 \mathrm{~V} / \mathrm{m}$ intensity the concentration of ROS increased from $x=54.64$ to $x=67.36$ (Table I).

The enzymatic activity of superoxide dismutase in blood platelets decreased significantly in relation to the control values after exposure to EMF of both intensity $150 \mathrm{~V} / \mathrm{m}$ and $220 \mathrm{~V} / \mathrm{m}$, regardless of the exposure time (Figure 3). The most prominent change of this enzyme activity in relation to the control sample was observed after $60-\mathrm{min}$ exposure to the field of $220 \mathrm{~V} / \mathrm{m}$ intensity (from $x=3556.41$ to $x=1084.83)$. However, after 30-

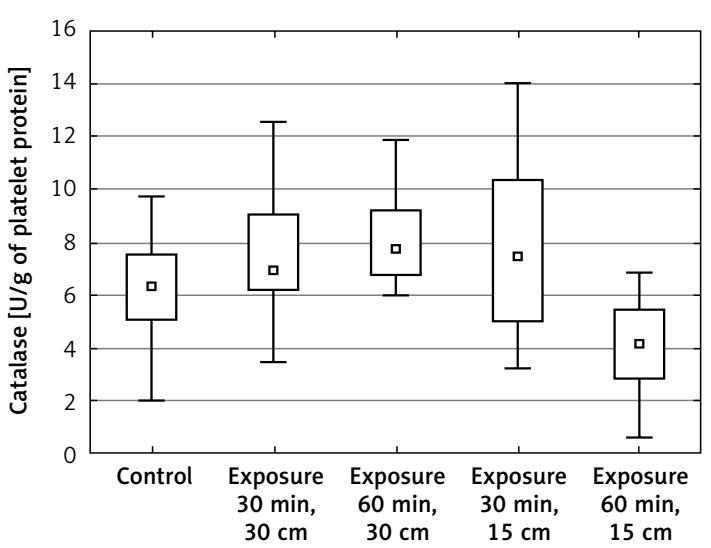

- Median $\square 25-75 \% \quad$ I Non-outliers range

Figure 4. Enzymatic activity of catalase (CAT) in blood platelets exposed to electromagnetic radiation dependent on the intensity and exposure time $(n=37)$

min exposure to the field of this intensity the activity of the enzyme decreased from $x=3556.41$ to $x=1364.78$. After 30-min exposure to EMF of $150 \mathrm{~V} / \mathrm{m}$ intensity the decrease of superoxide dismutase activity was noted from the initial value $x=3556.41$ to $x=1933.06$. After 60-min exposure to the field of this intensity the value of SOD activity decreased to $x=1906.75$ (Table II).

The activity of catalase in blood platelets exposed to electromagnetic radiation increased after both 30-min exposure (from $x=6.28$ to $x=6.91$ ) and 60-min exposure (from $x=6.28$ to $x=7.77$ ) at the field intensity $150 \mathrm{~V} / \mathrm{m}$ in relation to the control values (Figure 4). During 30-min exposure to EMF of $220 \mathrm{~V} / \mathrm{m}$ intensity, the activity of cata-

Table II. Statistical analysis of the enzyme activity of superoxide dismutase (SOD-1) in blood platelets treated with electromagnetic radiation of the defined parameters and the time of exposure

\begin{tabular}{|c|c|c|c|c|c|}
\hline \multirow{2}{*}{$\begin{array}{l}\text { Name of the } \\
\text { characteristic }\end{array}$} & \multirow{2}{*}{$\begin{array}{l}\text { Control } \\
\text { group }\end{array}$} & \multicolumn{4}{|c|}{ Exposure to electromagnetic radiation of the parameters and time } \\
\hline & & $\begin{array}{l}\text { Intensity: } \\
150 \mathrm{~V} / \mathrm{m}(30 \mathrm{~cm}) \\
30 \mathrm{~min} \\
\text { Group I }\end{array}$ & $\begin{array}{l}\text { Intensity: } \\
150 \mathrm{~V} / \mathrm{m}(30 \mathrm{~cm}) \\
60 \mathrm{~min} \\
\text { Group II }\end{array}$ & $\begin{array}{l}\text { Intensity: } \\
220 \mathrm{~V} / \mathrm{m}(15 \mathrm{~cm}) \\
30 \mathrm{~min} \\
\text { Group III }\end{array}$ & $\begin{array}{l}\text { Intensity: } \\
220 \mathrm{~V} / \mathrm{m}(15 \mathrm{~cm}) \\
60 \mathrm{~min} \\
\text { Group IV }\end{array}$ \\
\hline Number of individuals & 37 & 37 & 37 & 37 & 37 \\
\hline Minimum & 1757.79 & 463.97 & 406.63 & 436.65 & 225.50 \\
\hline Maximum & 5638.57 & 3515.10 & 3264.86 & 2507.60 & 2206.04 \\
\hline Median & 3556.41 & 1933.06 & 1906.75 & 1364.78 & 1084.83 \\
\hline Arithmetic mean & 3429 & 1818.98 & 1809.13 & 1383.01 & 1077.43 \\
\hline SD & 1147.98 & 906.41 & 857.38 & 623.47 & 516.18 \\
\hline Skewness & 0.23 & 0.12 & -0.02 & 0.04 & 0.40 \\
\hline Statistical analysis & \multicolumn{5}{|c|}{$\begin{array}{l}\text { Test Anova rang Kruskala_Wallisa } H=75,81, p<0.001 \\
\text { Test } Z^{k, I}{ }_{\text {Manna-Whitneya }}=5.19, p<0.001 \\
\text { Test } Z^{k, I I}{ }_{\text {Manna-Whitneya }}=5.39, p<0.001 \\
\text { Test } Z^{k, \text { III }} \text { Manna-Whitneya }=6.62, p<0.001 \\
\text { Test } Z^{\mathrm{k}, \mathrm{IV}}{ }_{\text {Manna-Whitneya }}=7.11, p<0.001\end{array}$} \\
\hline
\end{tabular}


Table III. Statistical analysis of enzyme activity of catalase in blood platelets exposed to electromagnetic radiation of defined parameters and exposure time

\begin{tabular}{|c|c|c|c|c|c|}
\hline \multirow{2}{*}{$\begin{array}{l}\text { Name of the } \\
\text { characteristic }\end{array}$} & \multirow{2}{*}{$\begin{array}{l}\text { Control } \\
\text { group }\end{array}$} & \multicolumn{4}{|c|}{ Exposure to electromagnetic radiation of the parameters and time } \\
\hline & & $\begin{array}{c}\text { Intensity: } \\
150 \mathrm{~V} / \mathrm{m}(30 \mathrm{~cm}), \\
30 \mathrm{~min} \\
\text { Group I }\end{array}$ & $\begin{array}{c}\text { Intensity: } \\
150 \mathrm{~V} / \mathrm{m}(30 \mathrm{~cm}), \\
60 \mathrm{~min} \\
\text { Group II }\end{array}$ & $\begin{array}{c}\text { Intensity: } \\
220 \mathrm{~V} / \mathrm{m}(15 \mathrm{~cm}), \\
30 \mathrm{~min} \\
\text { Group III }\end{array}$ & $\begin{array}{c}\text { Intensity: } \\
220 \mathrm{~V} / \mathrm{m}(15 \mathrm{~cm}), \\
60 \mathrm{~min} \\
\text { Group IV }\end{array}$ \\
\hline Number of individuals & 37 & 37 & 37 & 37 & 37 \\
\hline Minimum & 2.02 & 3.46 & 5.96 & 3.23 & 2.02 \\
\hline Maximum & 9.73 & 12.55 & 13.40 & 14.04 & 6.91 \\
\hline Median & 6.28 & 6.91 & 7.77 & 7.45 & 4.15 \\
\hline Arithmetic mean & 6.26 & 7.46 & 8.11 & 8.15 & 4.14 \\
\hline SD & 1.81 & 2.16 & 1.72 & 3.11 & 1.43 \\
\hline Skewness & -0.15 & 0.70 & 1.08 & 0.17 & 0.07 \\
\hline Statistical analysis & \multicolumn{5}{|c|}{ 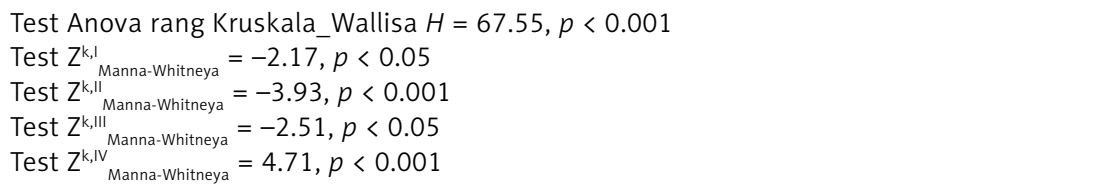 } \\
\hline
\end{tabular}

lase increased significantly in relation to the initial values (from $x=6.28$ to $x=7.45$ ), whereas after 60-min exposure it decreased significantly (from $x=6.28$ to $x=4.15$ ) (Table III).

The measurement of malondialdehyde concentration demonstrated a statistically significant increase in blood platelets after 30-min exposure to an electromagnetic field of $220 \mathrm{~V} / \mathrm{m}$ intensity in relation to the initial values (from $x=3.18$ to $x=4.41$ ) (Figure 5, Table IV).

\section{Discussion}

Assessment of risks from electromagnetic fields based on in vitro studies seems to be one of the most authoritative and reliable methods. It is known that low-frequency radiation penetrates deep into the tissue and is absorbed to a small extent by the surrounding cellular environment. It is also known that changes taking place at the cellular level account for the response of an organism as a whole. The production of toxic reactive oxygen species and the mechanisms for their neutralization determine the pro-oxidant-antioxidant balance. Disruption of this balance leads to pathologies because reactive oxygen species react with components of the cells. These reactions can have adverse and even dangerous health effects, and they can cause the so-called free radical diseases. Pathological implications of ROS and oxidative stress reactions include, among others, atherosclerosis, diabetes [8], rheumatoid arthritis, multiple sclerosis, and Parkinson's disease, in which increased ROS production by phagocytes and an elevated plasma MDA level were observed [9]. Other studies also proved that ROS and anti-

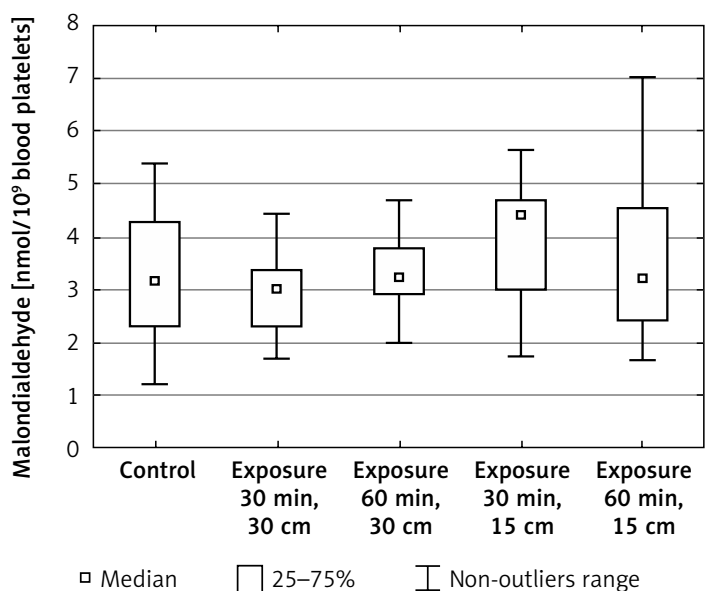

Figure 5. Concentration of malondialdehyde (MDA) in blood platelets exposed to electromagnetic radiation dependent on the intensity and exposure time $(n=37)$

oxidants stimulate HIV replication in an organism [10]. In the opinion of other researchers, ROS level could be a universal indicator, which does not exclude the individualized approach in each episode of infective endocarditis (IE). The ROS may have a particular implication in high-risk patients, especially when the assays of inflammatory markers are confusing [11].

In children, hydrocephalus, Down's syndrome, autism, brain injury and brain cancer are associated with oxidative stress [12]. Another study revealed increased levels of MDA and CO levels in the chronic fatigue syndrome (CFS) group. The researchers concluded that oxidative stress is present in the group of CFS patients [13]. 
Table IV. Statistical analysis of changes in levels of malondialdehyde in blood platelets exposed to electromagnetic radiation of defined parameters and exposure time

\begin{tabular}{|c|c|c|c|c|c|}
\hline \multirow{2}{*}{$\begin{array}{l}\text { Name of the } \\
\text { characteristic }\end{array}$} & \multirow{2}{*}{$\begin{array}{l}\text { Control } \\
\text { group }\end{array}$} & \multicolumn{4}{|c|}{ Exposure to electromagnetic radiation of the parameters and time } \\
\hline & & $\begin{array}{l}\text { Intensity: } \\
150 \mathrm{~V} / \mathrm{m}(30 \mathrm{~cm}) \\
30 \mathrm{~min} \\
\text { Group I }\end{array}$ & $\begin{array}{l}\text { Intensity: } \\
150 \mathrm{~V} / \mathrm{m}(30 \mathrm{~cm}) \\
60 \mathrm{~min} \\
\text { Group II }\end{array}$ & $\begin{array}{l}\text { Intensity: } \\
220 \mathrm{~V} / \mathrm{m}(15 \mathrm{~cm}) \\
30 \mathrm{~min} \\
\text { Group III }\end{array}$ & $\begin{array}{l}\text { Intensity: } \\
220 \mathrm{~V} / \mathrm{m}(15 \mathrm{~cm}) \\
60 \mathrm{~min} \\
\text { Group IV }\end{array}$ \\
\hline Number of individuals & 36 & 36 & 36 & 36 & 36 \\
\hline Minimum & 1.20 & 1.69 & 2.01 & 1.74 & 1.66 \\
\hline Maximum & 5.41 & 9.65 & 5.24 & 5.67 & 7.04 \\
\hline Median & 3.18 & 3.00 & 3.24 & 4.41 & 3.24 \\
\hline Arithmetic mean & 3.15 & 3.25 & 3.37 & 4.00 & 3.48 \\
\hline SD & 1.24 & 1.46 & 0.73 & 1.15 & 1.35 \\
\hline Skewness & 0.01 & 2.78 & 0.64 & -0.55 & 0.66 \\
\hline Statistical analysis & \multicolumn{5}{|c|}{$\begin{array}{l}\text { Test Anova rang Kruskala_Wallisa } H=13.23, p<0.01 \\
\text { Test } Z^{\mathrm{k}, I}{ }_{\text {Manna-Whitneya }}=0.16, p>0.05 \\
\text { Test } Z^{\mathrm{k}, \mathrm{II}} \text { Manna-Whitneya }=-0.87, p>0.05 \\
\text { Test } Z^{\mathrm{k}, \mathrm{III}}{ }_{\text {Manna-Whitneya }}=-2.86, p<0.01 \\
\text { Test } Z^{\mathrm{k}, \mathrm{IV}}{ }_{\text {Manna-Whitneya }}=-0.75, p>0.05\end{array}$} \\
\hline
\end{tabular}

In our studies determining the effect of electromagnetic radiation of $1 \mathrm{kHz}$ frequency and $150 \mathrm{~V} / \mathrm{m}$ intensity (occurring at the distance of $30 \mathrm{~cm}$ from the monitor) and $220 \mathrm{~V} / \mathrm{m}$ (occurring at the distance of $15 \mathrm{~cm}$ from the monitor) on oxygen metabolism of blood platelets, a statistically significant increase was observed in the concentration of ROS regardless of the parameters and the exposure time. Their highest increase in relation to the control sample was observed after exposure to an electromagnetic field of $220 \mathrm{~V} / \mathrm{m}$ intensity for $60 \mathrm{~min}$. The results of the measurement of ROS generation are a proof of the negative impact of the electromagnetic field generated by LCD monitors on the human organism. It is particularly harmful during long work with a computer or other appliances with an LCD monitor when the head is at a distance of $15 \mathrm{~cm}$ from the screen.

Other researchers who investigated the impact of electromagnetic radiation of extremely low frequency (ELF, $3 \mathrm{~Hz}-3 \mathrm{kHz}$ ) obtained similar results. Canseven et al. observed in their studies the effect of a low frequency electromagnetic field ( $50 \mathrm{~Hz}$ and 1, 2 and $3 \mathrm{mT}$ ) on the level of free radicals, the natural antioxidant system and respiratory burst system activities in the heart and liver of guinea pigs. They demonstrated that the intensity and exposure time have an impact on increased production of free radicals and on the changes in the activity of antioxidant enzymes [14].

Furthermore, Chu et al. in their studies on the effect of EMF of $60 \mathrm{~Hz}$ frequency and $2.3 \mathrm{mT}$ induction on rat cerebellar cells demonstrated the increase of ROS with simultaneous decrease of SOD activity after 3-hour exposure [15]. Superox- ide dismutase (SOD-1), protecting a cell against the cytotoxic effect of the superoxide anion radical, was another tested parameter. A reaction was carried out of superoxide anion dismutation to molecular oxygen and hydrogen peroxide. The superoxide anion radical is a very dangerous compound, mainly due to the relatively long half-life, and it diffuses easily from the place of its formation to other cellular structures. Many studies have reported the change of superoxide dismutase activity under the effect of electromagnetic radiation of different parameters. Exposing erythrocytes and blood platelets to electromagnetic radiation generated by cellular phones, lower levels of superoxide dismutase enzymatic activity were determined [16].

Xie et al. in their studies noted a decrease of SOD activity in human cells exposed to 12-hour EMF of $200 \mathrm{kV} / \mathrm{m}$ and $400 \mathrm{kV} / \mathrm{m}$ intensity. They also observed an increase of MDA concentration in these cells [17].

The measurement of superoxide dismutase enzymatic activity in our studies demonstrated its decrease in relation to the control values after exposure to an EMF of both $150 \mathrm{~V} / \mathrm{m}$ and $220 \mathrm{~V} / \mathrm{m}$ intensity regardless of the exposure time. The observed changes in the activity of this antioxidant defence protein confirmed that under the effect of electromagnetic radiation generated by LCD monitors there occurs a process of uncontrolled generation of reactive oxygen species. The subsequently observed significant decrease of superoxide dismutase activity was probably caused by the excessively high amount of ROS generated due to electromagnetic radiation. The results of the studies 
also revealed a correlation between the exposure time and the level of the decrease of SOD activity. During longer - 60-min - exposure the changes in the activity are more pronounced, which proved that together with the increase of exposure time there occurs distinct impairment of pro-oxidant/ antioxidant balance. The results of these studies also reveal a correlation between the field intensity and the intensity of changes in the enzyme. The stronger the magnetic field, the more significant is the decrease in the activity, which in consequence leads to enhanced oxidative stress.

Catalase, the next tested parameter of oxygen metabolism, converts the disproportionate hydrogen peroxide (the substrate of a reaction catalysed by SOD) to water and oxygen. The activity of this enzyme in blood platelets exposed to electromagnetic radiation increased after both 30- and 60-min exposure at the field intensity of $150 \mathrm{~V} / \mathrm{m}$ in relation to the control values. During 30-min exposure to EMF of $220 \mathrm{~V} / \mathrm{m}$ intensity, catalase activity increased significantly in relation to the initial values, whereas after 60-min exposure it decreased significantly. The obtained result may point to a compensatory increase of catalase activity in relation to the increase of ROS generation after exposure to electromagnetic radiation. Higher intensity and longer exposure time (60 min) caused impairment of antioxidant defence capacity manifested by a final decrease of catalase activity below the value of the control sample. Similar results were obtained in the studies evaluating the effect of an electromagnetic field of $1000 \mathrm{~Hz}$ frequency and $0.5 \mathrm{mT}$ magnetic induction on catalase activity. It was found to increase significantly after 30-min exposure, which correlated with the increase of reactive oxygen species generation. However, further measurements demonstrated the decrease of this enzyme activity in relation to the values of the control samples [18].

Other researchers reported a decrease of CAT activity after 8-min exposure of rats to EMF of $70 \mu \mathrm{T}$ induction, which correlated with the decrease of $\mathrm{H}_{2} \mathrm{O}_{2}$ concentration [19]. The impairment of pro-oxidant-antioxidant balance manifested by uncontrolled increase of ROS can also lead to lipid peroxidation. It is a process of rapid destruction of cell membranes due to oxidation of their components - phospholipids composed of unsaturated fatty acids. This results in excessive synthesis of lipid peroxides and transformation of polyunsaturated fatty acids into biological active substances. Thus, lipid peroxidation produces numerous consequences such as changes in the structure and fluidity of cell membrane, disturbances in membrane transport, changes in the activity of cell membrane enzymes and damage of protein receptors found in membrane structures [20].
In the course of our studies malondialdehyde (MDA) was used as a marker of lipid peroxidation. It is one of the end-products of this process, belonging to the compounds reacting with thiobarbituric acid. The increase in MDA level in combination with increased ROS generation points to the damage of cell membranes by ROS. A statistically significant increase of MDA level was demonstrated in blood platelets after 30-min exposure to EMF of $220 \mathrm{~V} / \mathrm{m}$ intensity in relation to the initial values. It proves insufficient adaptation of cellular antioxidant mechanisms which protect, among other things, against oxidation of cell membrane components.

The studies carried out in other centres obtained similar results. Balci et al. in an experiment performed on the cells of rat cornea and lens observed a negative effect of radiation on pro-oxidant-antioxidant balance. These authors noted an increase in MDA level in rats exposed to radiation emitted from the distance of $20 \mathrm{~cm}$ from the monitor [21]. Lai et al. also found that radiation of power frequency and 0.1-0.5 mT induction induced the occurrence of oxidative stress in brain cells of the rat [22].

In another experiment, rats were exposed to a magnetic field of $70 \mathrm{mT}$ intensity, once a day for 8 min for 7 consecutive days. The results demonstrated that the MDA level in plasma increased initially, and after the second week of exposure to the magnetic field it decreased, which the author explained by decreased generation of ROS observed in the experiments. It correlated with the decreased SOD and CAT activity [23].

Countless research studies concerning the impact of electromagnetic radiation of different parameters on the matter prove the negative effect of this factor on health and life of living organisms. Nevertheless, there are studies showing contradictory results as well. Kang et al. reported that combined exposure of RF radiation (CDMA at $2 \mathrm{~W}$ / $\mathrm{kg}$ plus WCDMA at $2 \mathrm{~W} / \mathrm{kg}$ for $2 \mathrm{~h}$ ) did not cause any observable adverse effects on the intracellular ROS level in neuronal cell models: U87 human glioma cells, PC12 rat pheochromocytoma cells, and SH-SY5Y human neuroblastoma cells [24].

Höytö et al. also reported no effect in SH-SY5Y and $\mathrm{L} 929$ (mouse fibroblasts) cell lines under GSM (SAR of $5 \mathrm{~W} / \mathrm{kg}$ for $1 \mathrm{~h}$ ) exposure [25].

In the ELF frequency Kabuto et al. reported no effect following exposure of mice to ELF-EMFs $(60 \mathrm{~Hz}, 0.2-1.2 \mathrm{mT})$. The study demonstrated that neither ROS generation nor lipid peroxidation could be detected in brain homogenates of exposed mice [26].

Another experiment demonstrated that the effect of ELF-MF irradiation on oxidative stress parameters depends on the time of animal exposure 
to the magnetic field. The aim of the study was to assess the effect of ELF-MF parameters most frequently used in magnetotherapy on ROS generation in brain tissue of experimental animals depending on the time of exposure to this field. The study showed that ELF-MF applied for $30 \mathrm{~min} /$ day for 10 days can affect free radical generation in the brain. Prolongation of the exposure to ELF-MF (60/min/day) caused adaptation to this field [27].

The results of experiments do not lead to unequivocal conclusions. Despite numerous studies, it was impossible to identify in full statistical correlations between electromagnetic radiation of defined parameters and specific somatic effects in a human organism. In the field of electromagnetic radiation it is extremely difficult to demonstrate that there are cause and effect relationships. The interpretation of the observed phenomena is difficult because the effects of the activity of electromagnetic fields are usually weak, transitory, and difficult to reconstruct and repeat [28].

Moreover, the effects of electromagnetic fields on biological systems depend on the frequency range of the employed signals, as well as on their characteristics such as amplitude, intensity, modulation, waveform, and exposure time [27]. The contradictory results may also arise from mistakes made when reproducing exactly the same environmental conditions of the exposed case in term of vibrations and temperature variations. Description of the ELF-EMFs homogeneity within the used exposure device and temperature control is lacking in the majority of the exposure configurations. At the ELF frequencies, sham exposure should be represented by coil systems using separated strand cables wrapped in parallel to enable the currents to flow also in antiparallel directions.

Moreover, differences in cell lines [24, 25], material (human or animal cells), and experimental methods (laboratory exposure set-ups often present limitations without proper dosimetry) used for in vitro exposure might explain, in part, these conflicting findings. Different components and cell structures can be the site of electromagnetic radiation in an organism. For example, the high metabolic rate and lipid-rich composition of the nervous system make this organ particularly sensitive to oxidative damage. Human blood platelets, used in our study, are also very sensitive to any changes.

The established regulations on health hazards are based on two key mechanisms of interaction with biological systems, one elicited by direct current (DC) and extremely low frequency (ELF $1 \mathrm{~Hz}$ - $100 \mathrm{kHz}$ ) sources, and the other by RF (radiofrequency $100 \mathrm{kHz}-3 \mathrm{GHz}$ ) and $\mathrm{MW}$ (microwaves $>300 \mathrm{GHz}$ ) exposures.

In the field of RF, a major experimental problem is the definition of non-thermal effects and how to distinguish them from direct and indirect thermal effects (low-level EMF exposure does not induce a thermal effect). Most of the RF-EMF radiation absorbed is converted into increased thermal energy of the system, which is responsible for most effects observed in biological systems [24, 25].

Besides, it is not accurate to perform an SAR calculation that does not take into consideration the different conductivities and densities of the animal tissues - rats and mice (SAR is defined as the $a b$ sorbed dose in the unitary mass of the biological target within a certain time interval) $[24,25]$.

Furthermore, negative effects of EMFs in the form of specific diseases are usually observed after a long time of latency, and they become apparent often after years and even in further generations. However, it is known that the strength of the EMF depends on the distance of its source, and the intensity of radiation decreases rapidly with the distance from this source. This has been confirmed by our own and other authors' studies. Chen et al. and Zyss, assessing the exposure to EMF emitted from monitors dependent on the distance from the appliance and also on the exposure time, came to the conclusion that a person should maintain the longest possible distance and shorten the time of exposure when working next to monitors [29, 30].

In conclusion, the observed changes (the increase) within the scope of the generation of reactive oxygen species in blood platelets exposed to electromagnetic radiation emitted by the display screens are substantially and proportionally dependent on the exposure time and the field intensity. The decrease in the antioxidant activity of superoxide dismutase and the increase or decrease (after longer and stronger radiation) in catalase activity may be the cause of adverse effects of EMF exposure on oxygen metabolism in blood platelets. The in vitro study showed that the oxidative stress which develops after EMF exposure may lead to lipid peroxidation in the cell membrane of blood platelets, which is expressed by a significant increase in malondialdehyde concentration. Electromagnetic radiation emitted by the display screens may cause dysfunction of the adaptability of the body in antioxidant systems of somatic cells, which can significantly interfere with the physiological functioning.

\section{Conflict of interest}

The authors declare no conflict of interest.

\footnotetext{
References

1. Asanowi T, Rakov A. The state of health of persons working in electric fields of outdoor 400 and $500 \mathrm{kV}$ switch-yard. Gin. Tr Prof Zabol 1966; 10: 50-2.
} 
2. Röösli M, Egger M, Pfluger D, Minder C. Cardiovascular mortality and exposure to extremely low frequency magnetic fields: a cohort study of Swiss railway workers. Environ Health 2008; 7: 35.

3. Merzenich H, Schmiedel S, Bennack S, et al. Childhood leukemia in relation to radio frequency electromagnetic fields in the vicinity of TV and radio broadcast transmitters. Am J Epidemiol 2008; 168: 1169-78.

4. Schuz J, Ahlbom A. Exposure to electromagnetic fields and the risk of childhood leukaemia: a review. Radiat Prot Dosimetry 2008; 132: 202-11.

5. Misra H, Fridovich J. The role of superoxide anion in the autooxidation of epinephrine and a simple assay superoxide dismutase. J Biol Chem 1972; 247: 3170-5.

6. Beers L, Sizer T. Spectrofotometric method for measuring the breakdown of hydrogen peroxide by catalase. J Biol Chem 1952; 195: 133-40.

7. Placer Z. Estimation of products of lipid peroxidation malonyldialdehyde in biochemical systems. Anal Bioch 1966; 16: 359-64.

8. Beisswenger PJ, Szwergold BS, Yeo KT. Glycated proteins in diabetes. Clin Lab Med 2001; 21: 53-78.

9. Adams JDJ, Chang ML, Klaidman L. Parkinson's disease-redox mechanizm. Curr Med Chem 2001; 8: 809-14.

10. Israel N, Gougerot-Pocidalo MA. Oxidative stress in human immunodeficiency virus infection. Cell Mol Life Sci 1997; 53: 864-70.

11. Ostrowski S, Marcinkiewicz A, Nowak D, Zwoliński R, Jaszewski R. Comparison of the clinical application of reactive oxygen species and inflammatory markers in patient with endocarditis. Arch Med Sci 2012; 8: 244-9.

12. Granot E, Kohen R. Oxidative stress in childhood - in health and disease states. Clin Nutr 2004; 23: 3-11.

13. Tomic S, Brkic S, Maric D, Novakov Mikic A. Lipid and protein oxidation in female patients with chronic fatigue syndrome. Arch Med Sci 2012; 8: 886-91.

14. Canseven AG, Coskun S, Sevhan N. Effects of various extremely low frequency magnetic fields on the free radical processes, natural antioxidant system and respiratory burst system activities in the heart and liver tissues. Indian J Biochem Biophys 2008; 5: 326-31.

15. Chu LY, Lee JH, Nam YS, et al. Extremely low frequency magnetic field induces oxidative stress in mouse cerebellum. Gen Physiol Biophys 2011; 30: 415-21.

16. Moustafa Y, Moustafa R, Belacy A, Abou-El-Ela S, Ali F. Effects of acute exposure to the radiofrequency fields of cellular phones on plasma lipid peroxide and antioxidase activities in human erythrocytes. J Pharm Biomed Anal 2001; 26: 605-8.

17. Xie XJ, Zeng GY, Guo Y, Guo GZ, Zeng LH, Ren DQ. Effect of EMP on superoxide dismutase and malondialdehyde in $\mathrm{K} 562$ cells. 7th Asian-Pacific Conference on Medical and Biological Engineering IFMBE Proceedings 2008; 19: 455-7.

18. Buczyński A, Pacholski K, Talar J, Jerominko A, Dziedziczak-Buczyńska M. Estimation of enzymatic activity of catalase (CAT) and superoxide dismutase (SOD-1) in blood platelets exposed to electromagnetic radiation emitted in vehicles. Fizjoter Pol 2004; 4: 385.

19. Paluszak J, Sosnowski P, Mikrut K. The effect of pulsating magnetic field on antioxidant enzymes activity in the rat's blood. Acta Bio-Opt Inf Med 1999; 5: 1-5.

20. Zmyślony $M$, Jajte J. The role of free radicals in mechanisms of biological function exposed to weak, constant and net magnetic fields. Med $\operatorname{Pr} 1998 ;$ 49: 177-86.

21. Balci M, Namuslu M, Devrim E, Durak I. Effects of computer monitor-emitted radiation on oxidant/antioxi- dant balance in cornea and lens from rats. Mol Vision 2009; 15: 2521-5.

22. Lai H, Singh N. Magnetic-field-induced DNA strand breaks in brain cells of the rat. Environ Health Perspect 2004; 112: 687-9.

23. Paluszak J. The antioxidative enzymes activity in blood of rats exposed to long-term magnetic field. Med Life 2000; 5: 8-10.

24. Kang KA, Lee HC, Lee JJ, et al. Effects of combined radiofrequency radiation exposure on levels of reactive oxygen species in neuronal cells. J Radiat Res 2013; 1: $1-12$.

25. Höytö A, Luukkonen J, Juutilainen J, Naarala J. Proliferation, oxidative stress and cell death in cell exposed to $872 \mathrm{MHz}$ radiofrequency radiation and oxidants. Radiat Res 2008; 170: 235-43.

26. Kabuto H, Yokoi I, Ogawa N, Mori A, Liburdy RP. Effects of magnetic fields on the accumulation of thiobarbituric acid reactive substances induced by iron salt and $\mathrm{H}_{2} \mathrm{O} 2$ in mouse brain homogenates or phosphotidylcholine. Pathophysiology 2001; 7: 283-8.

27. Ciejka E, Kleniewska P, Skibska B, Goraca A. Effect of extremely low frequency magnetic field on oxidative balance in brain of rats. J Physiol Pharmacol 2011; 62: 657-61.

28. Mosiński F, Wira A. Social reaction to the risk of the electromagnetic fields influence on health. ISE.pl 2001.

29. Chen CC, Hong XY, Shen GZ, Jin XP. Assessment of exposure to extremely low frequency magnetic field emitted from monitors. Zhonghua Yu Fang Yi Xue Za Zhi 2004; 38: 14-7.

30. Zyss T. Emission of electromagnetic radiation from selected monitors. Med Pr 1995; 46: 485-91. 